\title{
Knowledge, attitudes and practices regarding dengue fever in a sub- urban community in Sri Lanka
}

\author{
Gunasekara TDCP ${ }^{1}$, Velathanthiri VGNS ${ }^{2}$, Weerasekara $\mathrm{MM}^{1}$, Fernando $\mathrm{SSN}^{1}$, Peelawattage $\mathbf{M}^{1}$, \\ Guruge $\mathbf{D}^{\mathbf{1}}$, Fernando $\mathbf{S}^{\mathbf{1}}$ \\ ${ }^{\prime}$ Department of Microbiology, ${ }^{2}$ Medical Laboratory Science Unit, Faculty of Medical Sciences, University of \\ Sri Jayawardenapura, Gangodawila, Nugegoda, Sri Lanka
}

Correspondence: Dr.T.D.C.P. Gunasekara (tdcpgunasekara@gmail.com)

\begin{abstract}
Dengue is a major public health concern in Sri Lanka. In the recent dengue epidemics, majority of cases of dengue were reported from the Colombo district.

Aims: To determine the knowledge attitudes and practices (KAP) regarding dengue fever (DF) in a suburban population in the Colombo District.

Methods: The study was a prospective, cross sectional study and was conducted in 2005/2006 in a suburb of Colombo district. Data was collected using a pre-tested interviewer-administered questionnaire to assess the knowledge, attitudes and practices of 349 randomly selected residents in the Boralesgamuwa $\mathrm{MOH}$ area.

Results: Almost all the participants had heard of DF (98\%), the media being the most quoted source of information. Based on the scoring system, only $58 \%$ had satisfactory knowledge on the symptoms, management and transmission of dengue. Furthermore, $37 \%$ of the participants demonstrated satisfactory attitudes and $85 \%$ claimed to have used good practices towards dengue.

Conclusions: The participants demonstrated gaps in knowledge and poor attitude which may affect the level and frequency of preventive practices. Our findings highlight the need for further information, education and communication programs in the community.
\end{abstract}

Keywords: Dengue Fever, Knowledge, Attitudes, Practices, Sri Lanka

\section{Introduction}

Dengue fever (DF) is the most prevalent mosquitoborne infection that in recent decades has become a major international public health concern $(1,2)$. Dengue infection is caused by four dengue virus serotypes DENV-1, DENV-2, DENV-3, and DENV4 which are transmitted by Aedes aegypti and Aedes albopictus (1). A wide clinical spectrum has been classified by the World Health Organization (3) and it is possible for an individual to be infected with DF several times during his life time (4).

Sri Lanka experiences major epidemics of dengue each year. Several epidemics of dengue infection occurred in the years 2004, 2009 and 2010. In the years 2004, 2009 and 2010, 15, 230, 35010 and 34 105 cases were reported respectively (5). Although recent epidemics have effected the whole island, the majority of cases of dengue are still reported from the Colombo district (23\% in 2004) (6).

In the absence of a vaccine or specific antivirals to treat DF, vector control is one of the most important preventive measures in combating dengue. The recurrence of DF each year and the rising number of cases with each epidemic suggest that vector control efforts are probably ineffective and need to be improved. We carried out a study to determine the 
knowledge attitudes and practices (KAP) on DF of a suburban population in Colombo. We were unable to trace any previous studies to determine knowledge attitudes and practices regarding dengue in this area.

\section{Methods}

\section{Study setting}

The study was conducted in 2005/2006 in a suburb of Colombo district, Boralesgamuwa, which is located in the Western province. Three hundred and forty nine randomly selected community members were included in the study. Boralesgamuwa has an area of $11.1 \mathrm{~km}^{2}$, and a population of 62767 . In 2006 , there were 222 dengue suspected cases in Boralesgamuwa. The protocol of the project was reviewed and the ethical approval was granted by the Ethical review committee, University of Sri Jayawardhanepura.

\section{Study instrument}

Data was collected on the KAP of the residents regarding DF using a pretested intervieweradministered questionnaire. The participants who volunteered for the pretesting of the questionnaire were excluded from the main study, and minor changers were done after the pretesting. The questionnaire covered the following areas; (1) demographic information (area, gender, age, occupation, and education.), (2) attitude towards DF (3) knowledge about DF (symptoms, management, prevention,) (4) preventive practices and treatment for DF i.e. methods used to reduce breeding sites, reduce human mosquito contact (bed nets, repellents, and window screens), seeking treatment and home management of patients. The questionnaire comprised of both defined questions where the respondents could select the answer (yes / no questions) and open-ended questions.

\section{Study subjects}

As shown in table 1, the 349 respondents were divided into 6 age groups, where 165 belonged to 35 - 46 age group. The male to female ratio was $47 \%$. The level of education was considered as high, where $>70 \%$ having received secondary education. Among the participants $7 \%$ had received only primary education whereas $18 \%$ had received tertiary education. The proportion of employed persons in this study group was $36 \%$, whereas the unemployed proportion was $59 \%$.

Table 1: Socio-demographic characteristics of study population

\begin{tabular}{lcc}
\hline & $\begin{array}{c}\text { Number } \\
(\mathbf{N}=\mathbf{3 4 9})\end{array}$ & $\begin{array}{c}\text { Percent } \\
(\%)\end{array}$ \\
\hline Gender & & \\
$\quad$ Male & 163 & 46.7 \\
Female & 186 & 53.2 \\
\hline Age group & & \\
$\quad<20$ & 39 & 11.1 \\
$20-25$ & 27 & 7.7 \\
$26-35$ & 43 & 12.3 \\
$36-45$ & 165 & 47.2 \\
$45-55$ & 38 & 10.8 \\
$>55$ & 39 & 11.1 \\
\hline Occupation & & \\
Employed & 124 & 35.5 \\
Unemployed & 122 & 34.9 \\
Retired & 20 & 5.7 \\
Student & 83 & 23.7 \\
\hline Level of Education & & \\
$\quad$ Primary Education & 26 & 7.4 \\
Secondary Education & 246 & 70.4 \\
$\quad$ Tertiary Education & 62 & 17.7 \\
\hline
\end{tabular}

\section{Statistical analysis}

The data were analyzed using EXCEL version 2003 and each question was analyzed individually. KAPS were assessed using a scoring system. Responses to defined and open-ended questions were given one (1) and zero (0) ( 1 for yes/ correct answers and 0 for no/incorrect answers). These were added to arrive at a single value out of a possible total score of ten for knowledge, five for attitudes, and seven for practices. KAPS were assessed as satisfactory or unsatisfactory on an arbitrary cut-off point. Respondents who achieved more than $70 \%$ were considered as "satisfactory" for knowledge and practices and $75 \%$ for attitudes. Knowledge was assessed on ten questions which were grouped into symptoms, management and prevention. Similarly a positive attitude was assessed based on the ability of participants to give answers to several questions (Table 2). 
Table 2: Attitudes towards Dengue Fever

\begin{tabular}{lcc}
\hline Questions & $\begin{array}{c}\text { Number } \\
(\mathbf{N = 3 4 9 )}\end{array}$ & $\begin{array}{c}\text { Percent } \\
(\mathbf{\%})\end{array}$ \\
\hline I will treat a patient suspected of Dengue fever with home remedies & & \\
Yes & 175 & 50.1 \\
No & 159 & 45.5 \\
Not responded & 15 & 4.2 \\
\hline I must frequently check for mosquito breeding sites in my home and garden & \\
& 301 & 86.2 \\
\hline I do not check my neighbourhood for mosquito breeding sites due to; & & \\
Lack of time & 51 & 14.6 \\
It is not required of me & 25 & 7 \\
It may lead to conflicts with neighbours & 29 & 8 \\
\hline I am satisfied with my knowledge of DF and prevention measures & & \\
Yes & 210 & 60 \\
No & 149 & 40 \\
\hline I am motivated to find more information about DF & 118 & 33.8 \\
Yes & 231 & 66 \\
\hline No & & \\
\hline
\end{tabular}

Preventive practices were assessed based on nine questions grouped in to four categories such as (1) methods used to reduce breeding sites, (2) reduce human mosquito contact (3) seeking treatment and (4) home management of patients.

\section{Results}

\section{Knowledge about DF}

This study found that almost all (98\%) had heard of dengue fever and the main source of information was television broadcasts $(83 \%)$, while news papers $(76 \%)$ and radio broadcasts $(50 \%)$ also played an important role. They had received information also from health care officials (66\%), family and friends $(62 \%)$. Majority of the respondents had obtained information through multiple sources.

A high percentage of respondents were able to correctly identify symptoms of dengue such as high fever (94\%), vomiting (69\%), muscle pain $(85 \%)$ and headache (72\%). However, only $25 \%$ identified rash as a symptom. A low percentage identified stomach ache $(22 \%)$ as a symptom of DF. Only $0.5 \%$ of the participants had listed low platelet count as symptom of DF.
Knowledge and practices about complications and management of DF

When asked about the complications of DF, $46 \%$ said that dengue haemorrhagic fever (DHF) may occur. In the study group $15 \%$ were aware DF could be fatal. However, only $8 \%$ recognised shock as a complication and $32 \%$ were unaware of any complications. Whereas $73 \%$ were aware of the hemorrhagic manifestations such as vomit with blood (26\%), black stools (3\%), haematuria (1\%), rash $(34 \%)$, bleeding from gums and other sites $(13 \%)$. Some individuals (42\%) knew the danger of taking aspirin as a treatment. Some would not take paracetamol $(17 \%)$. or coriander $(8 \%)$, only $3 \%$ were aware that coloured drinks should be avoided during $\mathrm{DF}$ as it may confuse medical personnel in determining the presence of gastrointestinal bleeding. Alarmingly, 29\% respondents did not appear to have any idea of initial treatment of DF at home.

As shown in table 3 the majority of the participants $(98 \%)$ said that they would take the patient to a doctor. When asked what medications they would give to the patients the responses were paracetamol $(38 \%)$, aspirin $(2 \%)$ and boiled coriander $(10 \%)$ while $43 \%$ were unsure. Lesser percentage $(<2 \%$ each) were aware of the necessity of adequate rest, liquid intake and close observation of the patient which are very important practices. (Table 2 and Table 3). 
Table 3: Knowledge regarding Dengue Fever

\begin{tabular}{|c|c|c|}
\hline Questions & $\begin{array}{l}\text { Number } \\
(\mathrm{N}=349)\end{array}$ & $\begin{array}{c}\text { Percent } \\
(\%)\end{array}$ \\
\hline \multicolumn{3}{|c|}{ What are the symptoms of Dengue Fever? } \\
\hline High Fever & 329 & 94.27 \\
\hline Vomit & 241 & 69.05 \\
\hline Myalgia & 298 & 85.39 \\
\hline Headache & 251 & 71.92 \\
\hline Stomach ache & 78 & 22.35 \\
\hline Tiredness & 149 & 42.69 \\
\hline Blood passing with stools & 9 & 2.58 \\
\hline Rash & 93 & 26.60 \\
\hline Low platelet counts & 2 & 0.50 \\
\hline Diarrhoea & 6 & 1.72 \\
\hline Cold & 5 & 1.43 \\
\hline Cough & 54 & 15.47 \\
\hline \multicolumn{3}{|l|}{ What are the complications of DF? } \\
\hline Dengue haemorrhagic fever & 161 & 46.10 \\
\hline Shock & 29 & 8.30 \\
\hline Death & 53 & 15.10 \\
\hline Low platelet counts & 2 & 0.50 \\
\hline Dehydration & 3 & 0.85 \\
\hline Don't know & 103 & 29.40 \\
\hline \multicolumn{3}{|c|}{ What are the symptoms of DHF and DSS? } \\
\hline Haemorrhagic manifestations & 184 & 73.60 \\
\hline Vomit with blood & 91 & 26 \\
\hline Melena & 12 & 3.4 \\
\hline Haematuria & 4 & 1.1 \\
\hline Rash & 120 & 34.3 \\
\hline Bleeding from gums and other sites & 46 & 13.00 \\
\hline Cough & 38 & 10.8 \\
\hline \multicolumn{3}{|c|}{ What medication should not be given to a patient suspected of DF? } \\
\hline Aspirin & 148 & 42.40 \\
\hline Paracetamol & 60 & 17.10 \\
\hline Boiled coriander & 28 & 8.00 \\
\hline Coloured drinks & 11 & 3.15 \\
\hline Don't know & 102 & 29.20 \\
\hline \multicolumn{3}{|l|}{ How is DF transmitted? } \\
\hline By mosquitoes & 264 & 75.60 \\
\hline By water & 58 & 16.60 \\
\hline By garbage & 48 & 13.70 \\
\hline By air & 6 & 1.70 \\
\hline By flies & 9 & 2.50 \\
\hline \multicolumn{3}{|c|}{ Where do the Dengue mosquitoes breed? } \\
\hline Clean water & 316 & 90.50 \\
\hline Dirty water & 28 & 8.00 \\
\hline Don't know & 5 & 1.40 \\
\hline \multicolumn{3}{|c|}{ Can you identify the Dengue transmitting Mosquitoes? } \\
\hline Yes & 180 & 51.50 \\
\hline No & 169 & 48.40 \\
\hline \multicolumn{3}{|c|}{ What are the features of the Dengue transmitting mosquitoes? } \\
\hline Spots on the body & 141 & 40.4 \\
\hline Don't know & 39 & 11.1 \\
\hline \multicolumn{3}{|c|}{ At what time of the day do these mosquitoes bite? } \\
\hline Day time & 296 & 84.8 \\
\hline Night time & 4 & 1.1 \\
\hline Don't know & 38 & 10.8 \\
\hline
\end{tabular}




\section{Knowledge and practices about disease transmission and dengue vector}

Seventy six percent of the participants were aware that DF is transmitted by a mosquito vector. Among them $68 \%$ claimed that they could identify the dengue vector mosquito by detecting the spots (78\%). On the other hand $24 \%$ believed that dengue was transmitted by other methods such as water (17\%), garbage (14\%), air (2\%) and flies (2\%). Some participants had given multiple responses (Table 3 ).

Majority of the participants were aware of the correct breeding site of the mosquito (clean water) $(90 \%)$ and that they bite during the day ( $85 \%)$.

Regarding the measures to prevent contact with mosquitoes, many used mosquito nets $(72 \%)$ and repellent oils (41\%) as a preventive practice (Table 2). Equal percentages (27\%) of respondents felt that mosquito coils, mats and repellent sprays were useful. Lesser percentage $(<10 \%$ total) used other available methods such as fans, fumigation (insecticides, burning of cashew nut / coconut husks) and covering the ventilation holes with nets.

More than half of the study population (53\%) felt that it was necessary to remove or drain the standing water to reduce the mosquito breeding. Among them $43 \%$ said that they would bury the tyres and utensils which gather water, whereas 30\% would burn garbage. Further 3\% would fill up the tyres and containers with sand to prevent water accumulation. Only $2 \%$ would add salt to ant traps and standing water.

As a practice $57 \%$ said that they would check mosquito breeding sites in their neighbourhood. Among them $44 \%$ would participate in community cleaning campaigns (Shramadana), 29\% would request neighbours to clean their surroundings if necessary and $8 \%$ would inform the relevant health officers.

\section{Attitudes regarding dengue fever}

Fifty percent were of the opinion that home remedies can be used for treatment of dengue, while $46 \%$ did not agree (Table 4). While most of the participants $(86 \%)$ agreed that frequent checking of the mosquito breeding sites in their home and garden is required only $57 \%$ claimed to check for breeding sites in their neighbourhood. Among them $43 \%(n=150)$ said they were unable to check, due to lack of time $(33 \%)$, fear of conflicts with neighbours (18\%) or because it was unnecessary (11\%). When the respondents were asked to self assess their knowledge, $60 \%$ were confident that they had an adequate knowledge. (Table 4).

Based on the scoring system described in the methodology when the individual knowledge of each respondent was assessed, only $58 \%$ had satisfactory knowledge on the symptoms, management and transmission of Dengue. Whereas $37 \%$ of the respondents demonstrated satisfactory attitudes and $85 \%$ claimed to have used good practices towards dengue. (Table 5).

\section{Discussion}

Our study revealed that almost all respondents had heard about Dengue (98\%), the television and news papers being the main source of information. Similarly high percentages of dengue awareness was reported from Malaysia (98.5\%) (7), India (90\%) (8) and Pakistan (9). Mass media is a powerful tool in generating better awareness in dengue prevention and control $(10,11)$.

The scores for knowledge and attitudes of the respondents in our study were unsatisfactory whereas the scores for practices were high. High fever was the most quoted symptom comparable with similar studies done in Jamaica (12) and Laos (13), followed by myalgia, vomiting and headache, which may also be confused with the symptoms of common flu. This may imply a delay in seeking medical attention, and thus lead to complications. Only $0.5 \%$ recognized the importance of monitoring of low platelet counts, which is a key indicator of DF. However a better knowledge of the haemorrhagic manifestations of DHF could be seen as compared to Thailand and Pakistan $(9,14)$. Although the respondents were conscious of the importance of visiting the doctor when DF is suspected, there is a delay in seeking treatment due to the initial nonspecific presentation of dengue.

Our study sample demonstrated a better knowledge with regard to avoiding aspirin in dengue patients (42\%), when compared with a study conducted in Jamaica (12). Aspirin is a drug which is frequently used for reducing fever, and has the tendency to increase bleeding leading to complications in dengue patients. 
Table 4: Practices towards Dengue Fever

\begin{tabular}{|c|c|c|}
\hline Questions & $\begin{array}{l}\text { Number } \\
(\mathbf{N}=349)\end{array}$ & $\begin{array}{l}\text { Percent } \\
(\%)\end{array}$ \\
\hline \multicolumn{3}{|l|}{ Practices regarding home management of DF } \\
\hline I would treat the patient at home & 3 & 0.8 \\
\hline I will take the patient to a doctor & 341 & 97.7 \\
\hline Both & 5 & 1.4 \\
\hline \multicolumn{3}{|l|}{ It is safe to treat a DF patient with the following medications; } \\
\hline Aspirin & 6 & 1.70 \\
\hline Paracetamol & 133 & 38.10 \\
\hline Boiled corriander & 36 & 10.30 \\
\hline Don’t know & 150 & 42.90 \\
\hline \multicolumn{3}{|l|}{ Other } \\
\hline Adequate liquid intake & 8 & 2.20 \\
\hline Rest & 7 & 2.00 \\
\hline Close observation of patient for other symptoms & 6 & 1.70 \\
\hline \multicolumn{3}{|l|}{ I prevent mosquito bites by using the following methods ; } \\
\hline Mosquito nets & 250 & 71.63324 \\
\hline Mosquito coils / mats & 94 & 26.9341 \\
\hline Repellent oils & 142 & 40.68768 \\
\hline Repellent ointments and sprays & 93 & 26.64756 \\
\hline \multicolumn{3}{|l|}{ Other } \\
\hline Fumigation with insecticides or burning of kadju husks etc. & 7 & 2.005731 \\
\hline Use fans & 12 & 3.438395 \\
\hline Cover ventilation holes with nets & 2 & 0.573066 \\
\hline \multicolumn{3}{|c|}{ Methods used to prevent mosquito breeding in my home and garden are; } \\
\hline Remove/drain stagnant water & 185 & 53 \\
\hline Add salt to ant traps and standing water & 8 & 2.2 \\
\hline Add fish to ponds & 2 & 0.5 \\
\hline Add sand to fill up tyres and containers & 10 & 2.8 \\
\hline Burn garbage & 106 & 30.3 \\
\hline Bury tyres, containers, utensil etc. which can gather water & 149 & 42.7 \\
\hline \multicolumn{3}{|l|}{ I check for mosquito breeding sites in my neighbourhood. } \\
\hline Yes & 199 & 57 \\
\hline No & 150 & 43 \\
\hline \multicolumn{3}{|c|}{$\begin{array}{l}\text { I will contribute to the control of mosquito breeding areas in my neighbourhood by: } \\
\text { ( } N=199)\end{array}$} \\
\hline Participation in community campaigns (shramadana) & 152 & 43.5 \\
\hline Inform the health officers & 29 & 8.3 \\
\hline Inform the youth organizations & 3 & 0.8 \\
\hline Inform the media & 2 & 0.5 \\
\hline Request neighbours to keep their surroundings clean & 83 & 23.7 \\
\hline \multicolumn{3}{|l|}{ I receive information on $\mathrm{DF}$ by; } \\
\hline Newspapers & 265 & 75.9 \\
\hline Radio & 176 & 50.4 \\
\hline TV & 288 & 82.5 \\
\hline Leaflets & 234 & 67 \\
\hline $\mathrm{MOH} / \mathrm{PHI}$ & 230 & 65.9 \\
\hline Family and friends & 218 & 62.4 \\
\hline
\end{tabular}


Table 5: Percentage of individuals with satisfactory and unsatisfactory score in knowledge attitude and practice

\begin{tabular}{lccc}
\hline Score & Knowledge & Attitude & Practice \\
\hline Satisfactory & 58 & 37 & 81 \\
Unsatisfactory & 42 & 62 & 19 \\
\hline
\end{tabular}

As coffee coloured vomitus which is a symptom of DF only a minor population were aware of the need to avoid consumption of coloured drinks. Therefore the knowledge on home remedies which can be administered to a dengue patient need to be improved further. The knowledge on transmission was highly satisfactory, where majority knew that dengue is transmitted by day biting mosquitoes, who breeds in clean water. The importance of checking for mosquito breeding sites in their home and garden were acknowledged by most. This is a good trend in the community in preventing transmission. Among the participants $60 \%$ of the respondents though that they had sufficient knowledge about dengue, and this was further confirmed by our scoring system used in the study to evaluate knowledge (58\%).

Use of mosquito nets to prevent dengue was the most common practice, which may not be effective as mosquito nets are used at night whereas the dengue mosquitoes feed during day time. Use of mosquito repellent oils and ointments/sprays were also used commonly and are more effective as they can be applied on the body and the person can be ambulant. Some people also mentioned the use of smoke to drive away mosquitoes, by burning coconut husks or cashew nut shells as a traditional repellent in homes and work places. Although the community were aware of good practices regarding the elimination of mosquito breeding sites only a minor percentage would inform the relevant health authorities of unattended breeding sites in their community. Lack of communication between the community and relevant health authorities is a matter of concern and should be improved to prevent the current dengue outbreaks.

Our findings must be interpreted in the light of several potential limitations. The most apparent of which may be the fact that a cross sectional survey assesses relationships based on one point in time. As this was an interview based questionnaire it is possible that the participants may provide socially desirable responses specially regarding practices.
It was not possible to directly observe the practices in our study. However the majority of the participants were mature adults, who were active members of the community and therefore comprised a valid sample for assessment of KAPS. Unlike the other studies (15) where they had looked at only one or two aspects of the knowledge, we looked at the knowledge on dengue in three aspects i.e. knowledge on disease, treatment and prevention measures, which gave a robust picture on the disease.

In conclusion, although good practices were followed, there were gaps in knowledge and poor attitude among the participants which may affect the level and frequency of preventive practices. In spite of our study limitations our findings highlight the need for further information, education and communication programs in the community.

\section{Acknowledgement}

We thank Dr. J.M. Gunathilake, MOH, Boralesgamuwa for his kind assistance, Dr. (Mrs.) S. Prathapan (Department of Community Medicine, University of Sri Jayawardanepura) for advice on statistical analysis, Mrs. Fahrah Meedin, Mrs. Achala Bogahawatte, Mr. Rohan Mahendra, Mr. Dharshana Naulla, Mr. Wasantha Arunasiri for assistance with data collection.

\section{References}

1. Guzman MG, Halstead SB, Artsob H et al. Dengue: a continuing global threat. Nat Rev Microbiol, 2010; 8(12 Suppl): S7-16.

2. Vezzani D, Carbajo AE. Aedes aegypti, Aedes albopictus, and dengue in Argentina: current knowledge and future directions. Mem Inst Oswaldo Cruz, 2008; 103(1): 66-74.

3. WHO. Prevention and control of dengue and dengue haemorrhagic fever: comprehensive guidelines. WHO Regional Publication, 1999.

4. Oishi K, Saito M, Mapua CA, Natividad FF. Dengue illness: clinical features and pathogenesis. Jinfect Chemother, 2007; 13(3): 125-33.

5. Malavige GN, Ranatunga PK, Velathanthiri VG, et al. Patterns of disease in Sri Lankan dengue patients. Arch Dis Child, 2006; 91(5): 396-400.

6. Dengue in Sri Lanka: Sri Lanka Epidemiological Unit, 2011. 
7. Wan Rozita WM, Yap BW, Veronica S, et al. Knowledge, Attitude and Practice (KAP) Survey on Dengue Fever in an Urban Malay Residential Area in Kuala Lumpur Malaysian Journal of Public Health Medicine 2006; 6(2):62-67.

8. Acharya A, Goswami K, Srinath S, Goswami A. Awareness about dengue syndrome and related preventive practices amongst residents of an urban resettlement colony of south Delhi. J Vector Borne Dis, 2005; 42(3): 122-7.

9. Syed M, Syeda UR, Habib M, et al. Knowledge, attitudes and practices regarding dengue fever among adults of high and low socioeconomic groups. Journal of Pakistan Medical Association, 2010; 60(3): 243-247.

10. Swaddiwudhipong W, Lerdlukanavonge P, Khumklam P, et al. A survey of knowledge, attitude and practice of the prevention of dengue hemorrhagic fever in an urban community of Thailand. Southeast Asian J Trop Med Public Health, 1992; 23(2): 207-11.

11. Hairi F, Ong CH, Suhaimi A, Tsung TW, et al. A knowledge, attitude and practices (KAP) study on dengue among selected rural communities in the Kuala Kangsar district. Asia Pac J Public Health, 2003; 15(1): 37-43.
12. Shuaib F, Todd D, Campbell-Stennett D, Ehiri J, Jolly PE. Knowledge, attitudes and practices regarding dengue infection in Westmoreland, Jamaica. West Indian Med J, 2010; 59(2): 139-46.

13. Nalongsack S, Yoshida Y, Morita S, Sosouphanh K, Sakamoto J. Knowledge, attitude and practice regarding dengue among people in Pakse, Laos. Nagoya J Med Sci, 2009; 71(1-2): 29-37.

14. Koenraadt CJ, Tuiten W, Sithiprasasna R, et al Dengue knowledge and practices and their impact on Aedes aegypti populations in Kamphaeng Phet, Thailand. Am J Trop Med Hyg, 2006; 74(4): 692-700.

15. Tram T, Anh N, Hung N, Lan NLC. The impact of health education on mother's knowledge, attitude and practice (KAP) of dengue haemorrhagic fever. Dengue Bulletin. Dengue Bulletin, 2003; 27: 174-180. 